\title{
Research on Perfection of the Incentive Mechanism of Civil Servants
}

\author{
De-Ming LEI ${ }^{1 a^{*}}$, Hong-Zhen LIN ${ }^{2 b}$
}

${ }^{1}$ School of law and Economics, Wuhan University of Science and Technology Wuhan, China distinct addresses: 947 He Ping Street, Hubei Wuhan 430081, China

${ }^{2}$ School of Management, Wuhan University of Science and Technology Wuhan, China Distinct addresses: 947 He Ping Street, Hubei Wuhan 430081, China

leihaohaoyun@126.com

\section{Keywords: Civil Servants, Performance Appraisal, Incentive Mechanism}

\begin{abstract}
The purpose of this paper is to research Civil service incentive mechanism. Using the method of document study obtain related data in order to correctly understand the problem. Civil service incentive mechanism is an important part of the civil service management mechanism, which plays a positive role in the potential of mining civil servants. The paper analyzes the problems of the national civil service incentive mechanism, such as unreasonable position competition mechanism, imperfect assessment. The conclusion is that Effective measures and suggestion should be put forward to promote and perfect incentive mechanism. Improving the incentive system fully stimulate the working potential of the official staff to providing excellent public services.
\end{abstract}

\section{Introduction}

Human resource management in China is a new topic, and the research on the incentive mechanism of human resource management in public sector is still in the initial stage. The active and effective work of civil servants directly influences the realization of the basic administrative functions of the government organizations in the implementation of administrative management and social services. Therefore, it is important to establish and improve the incentive mechanism of civil servants, to study how to effectively use the incentive mechanism to promote public sector to attract and retain talent. The mechanism of national civil servants' motivation is the combination of internal force, internal force and external force. The key to the national civil service incentive is to increase the three forces, and to make the role of the same direction. Therefore, in practice can be divided into three types of mechanisms: stimulating mechanism, promoting mechanism and automatic mechanism

\section{The Meaning and Function of the Incentive Mechanism}

\section{The Meaning of the Incentive Mechanism}

Incentive mechanism is through a set of rational system to reflect the interaction between the main body and the object of the incentive object. The connotation of the incentive mechanism is the elements of the system. In the process of encouragement, reward and punishment are two most basic means of encouragement. Purpose of reward is the specific behavior of reinforcement, the purpose of punishment is for violation of the purposes of the organization, is not conducive to the development organization behavior for throttling. ${ }^{[1]}$ In organization management, reward and punishment are the effective means to restrict the behavior of people, and to ensure the people's behavior.

\section{The Role of Incentive Mechanism}

Once the incentive mechanism is formed, it will act on the organization system itself, so that it can be in a certain state, and further affect the organization's survival and development. The incentive mechanism has two kinds of properties, namely, to encourage and weak, that is to say, the incentive mechanism has a role in promoting the organization. 


\section{Firstly, Reasonable Incentive Mechanism of Positive Guidance Role}

The incentive mechanism is a certain incentive mechanism for employees in a certain way to meet the organizational expectations of behavior has repeatedly strengthened, and continuously enhance the role of the incentive mechanism, the organization continues to grow and grow. We call such an incentive mechanism to encourage the mechanism. ${ }^{[2]}$ Of course, in the good incentive mechanism, there must be a negative reinforcement and punishment measures to the staff of the organization does not meet the expectations of the behavior of the role play a constraint. The inspiration of the incentive mechanism to the management of employee's behavior is that the manager should be able to identify the real needs of the staff, and to meet the needs of the staff and the organization's objectives and measures to achieve effective combination.

\section{Secondly, the Negative Effect of the Unreasonable Incentive Mechanism}

Although the original intention of the designers of the incentive mechanism is to mobilize the enthusiasm of the staff and achieve the goal of the organization through the operation of the incentive mechanism. However, whether the incentive mechanism is not perfect, or the incentive mechanism is not feasible, it will play an active role in the work of a part of employees, which is the weak effect of the incentive mechanism. In an organization, the development of the organization will be limited until the decline is due to the long-term effects of the factors that play a positive role in the work of the staff. [3]Therefore, in order to eliminate the incentive mechanism, the incentive mechanism must be eliminated, and the effective incentive factors are to be eliminated.

\section{The Problems and Reasons of the Existing Problems of the Civil Service Incentive Mechanism in China}

\section{Unreasonable Rank Wage}

Post wages and salaries are the two main parts of the national civil service wages. Position salary according to job rank promotion, if two consecutive years of assessment can be promoted to a file position salary; wages according to wage policy adjustment: five consecutive years of assessment for qualified or three consecutive years of assessment can be promoted to a level of wages. Some sectors presents a competition appointment and empty posts are not substantive. ${ }^{[4]}$ The post rank salary incentive mechanism of civil servants is also a lack of sufficiently strong attraction.

\section{Unreasonable Assessment Incentive Mechanism}

First, because of the post target is not clear, the responsibility of the division of labor is not detailed, the assessment indicators are difficult to quantify, but the government departments and between the party and government departments, government departments, departments within different positions between the assessment content and standards cannot be unified, the results of the assessment is not strong.

Secondly, the year-end appraisal rating of spiritual and material incentives don't balance, material incentive is often symbolic, lack of irritating substances, therefore, in some localities and departments appear excellent grades. ${ }^{[5]}$ Real assessment of the results of the assessment are mostly mild, incompetent or basic title of the people almost nothing. Can be seen that the assessment of the incentive mechanism for the majority of civil servants, and not much of the constraint and incentive.

\section{Unscientific Post Competition Mechanism}

The incentive mechanism of competition is a widely used method in the employment of civil servants. The position of competition can be a middle level leadership position, it may also be a number of common positions; the object is generally the middle of the Department and the following civil servants. Through the competition for posts to make the civil service appointment of civil servants, the performance of the civil service appointment of competition and fairness. At present, there are two main problems in the competition for the competition. One is the interference of human factors. 
Because the competition is not to break the boundaries of the Department, is often limited to the internal departments, and in the democratic appraisal, on the individual, subjective judgment is often more than the objective evaluation, the evaluation result is difficult to correctly reflect the ability of the competition between the size, level, more reflect the good or bad. Two is the standard of service is not clear. The existing internal competition is often only determined by the competitive position, and no clear requirements for the job requirements, including quality requirements and capacity requirements. ${ }^{[6]}$ Due to the lack of a standard measure of internal and external factors, so sometimes competition mount guard incentive has become leading individual exclusion .

\section{Imperfect Promotions Channels of Civil Servants}

Firstly, civil servants longitudinal flow is too difficult, lack of reasonable lifting rules, the typical performance is cannot, can go up not down, in the promotion of civil servants speed is known to all. Promotion is the civil servants "Germany, energy, diligence, performance, low cost" of the full affirmation, the use of appropriate will be the civil servants themselves and other civil servants have an incentive and incentive effect. Promotion is not only to improve the enthusiasm of civil servants, but also an important manifestation of the realization of the value of civil servants.

Secondly, the civil service horizontal mobility is difficult, the lack of reasonable rules and regulations, the current area, the Department is only a small number of leading cadres can exchange. ${ }^{[7]}$ The main reason is that the legal system is not perfect, promotion opportunities, space is limited, civil service promotion is a prerequisite for the need to have vacancies, civil service job is to become Pyramid type, leadership positions are always less than non leadership positions, senior positions are always less than junior. Civil servants in our country most is section level cadres in the majority, more to promote the possibility of more small, most of the civil servants for a lifetime is a section level cadres.

\section{Measures of Improving the Civil Service Incentive Mechanism}

\section{Perfecting Salary System}

Public sector can establish a perfect incentive mechanism, will directly affect their survival and development. Incentive is the core of management, and salary incentive is the most important incentive mechanism, it is a kind of effective incentive means, it is more easy to control, but also easier to measure its effect, if can really play a good salary to the public sector staff incentive, you can achieve "win-win" purpose. And want to really play the pay management of the public will be to deepen the reform of the remuneration, to further improve the incentive mechanism.

The salary of civil servants, we can learn from the experience of enterprise human resources management incentive mechanism. The implementation of incentive mechanism in the enterprise human resource management in the public sector, there are many effective ways to learn from, therefore, we should also draw on the experience of the enterprise human resources management incentive mechanism.

\section{Establishing Fair and Impartial Performance Appraisal System}

First, the establishment of a scientific assessment to be based on. Traditional personnel management, mainly based on intuition, impression, random observation and with a simple record of the results of the work to assess the work, and thus the lack of strict, systematic, scientific assessment of the means, easy to cause the assessment of errors. Modern public sector human resource management requires the use of formal evaluation system, accurate, fair and positive assessment and evaluation of public servants. Assessment methods should be scientific, should be a combination of qualitative and quantitative, should make the assessment system, standardized. In such an assessment mechanism, it is possible to accurately determine the power and the individual's emotional color, as well as the absolute amount and relative amount of each person's contribution, in order to be fair to decide the rewards and punishments.

Secondly, rewards and punishments must be based on the results of fair and fair assessment. The implementation of public sector performance assessment of public officials, the civil service incentive process. [8] Taking "performance" as the main line of civil service examination is the core content of 
improving the incentive mechanism. The core of performance appraisal is: to the quality of personnel, heavy performance of cadres, pay attention to play and improve the ability of civil servants. The implementation of the civil service performance assessment, not only to stimulate the enthusiasm of the civil service than the performance, the contribution of the theory, but also for the discovery of talent, training personnel, the use of personnel to provide a reliable basis, so as to effectively promote the overall quality of the civil service.

\section{Perfecting Job Competition Mechanism}

First, to further expand the scope of competition. In addition to the requirements of political quality and basic education, the general should not set up other restrictions, for more people to participate in the examination competition, including the opportunity for the majority of workers, farmers and ordinary citizens. ${ }^{[9]}$ The appointment of civil servants, must be announced to the public, any position to meet the candidates who are open to open, the competitive examination, appointment of outstanding achievements.

Secondly, in the process, should be through the open examination, merit based recruitment. It follows the principle of openness, democracy, competition and merit, which requires the establishment of mechanisms to ensure the supervision and orderly, before the open examination, should be widely informed, so that people who meet the conditions and will have the opportunity to take the exam.

\section{Strengthening Training of Civil Servant Ability}

First of all, to carry out the training of professional knowledge, improve the knowledge literacy, improve the administrative efficiency, to implement the basic knowledge of the World Trade Organization in public sector, through training to learn the basic laws of market economy and the basic principles of the WTO, to enhance the awareness and response to international practice.

Secondly, to continue to carry out the law of administrative training, and promote the government functions to adapt to the requirements of the market economy, improve the official staff to adapt to the market economy and international practice in accordance with the law of administrative capacity; third, to strengthen the official staff, such as foreign language, computer skills training. ${ }^{[10]}$ Study and formulate the standard of ability and quality standards for all kinds of civil servants at all levels, and provide the scientific basis for the construction of scientific basis, establish a scientific training quality evaluation system, and realize the modernization of training means.

\section{Conclusion}

The quality of civil servants, ability, responsibility, cohesion, creativity, directly affect the government's administrative efficiency and operational level. With the change of the political, economic and cultural environment of the civil service system, it is necessary to improve the incentive mechanism, and fully mobilize the enthusiasm of the civil servants, so as to achieve the purpose of improving the efficiency of the administration. In short, the establishment and improvement of China's incentive mechanism is conducive to the initiative, enthusiasm and creativity of every official business. Because of the diversity of people's needs, multi level, the initiative, enthusiasm and creativity of the people are also varied. We should aim at the existing post competition mechanism is unreasonable, the assessment is not perfect, the incentive is not in place and other issues, it is proposed to solve the problem of countermeasures and measures to improve and comprehensive use of the incentive system, improve the promotion system, improve the management system and assessment system, strengthen training, to fully stimulate the potential of civil servants, to achieve the best administrative efficiency.

\section{Acknowledgement}

This research was financially supported by Hubei Province Education Department Foundation: Research on the Construction of Chinese Characteristics Socialist Accountability System Based on Hubei Province Accountability Long Term Mechanism. No.14zd014 


\section{References}

[1]Jiang Shuoliang. Incentive Mechanism of Civil Servant [J]. Chinese Administration, 2003, 6 (6): 24-25.

[2] Ma Lina. Analysis of The Incentive Mechanism of Civil Servants in Local Tax Authorities [J]. Financial Issues, 2013, (1): 167-171.

[3] Wang Yun. On The Establishment of China's Grass-Roots Civil Servants Incentive Mechanism [J]. People's Forum, 5, 2013 (2): 40-41.

[4]Shao Long, Ning Yu Liu Problems and Countermeasures of The On Our Country Civil Servants Incentive Mechanism Exist Perfect.Chizi, 2013, (08): 238-239.

[5] 2013 Colt Zhao The Problems and Countermeasures of Service Incentive Mechanism $[\mathrm{J}]$. Management World, 2013,4, (4): 170-171.

[6] Tian Siqian. Analysisof The Incentive Mechanism of Civil Servant and Improve [J]. Human Resources Management,2015, 9 (9): 7-9.

[7] Wang Yi. Based On Dill's Model of Motivation System The Civil Servants Incentive Mechanism [J]. Science and Technology Vision 2015, 13 (13): 59-61.

[8] Liu Jinzhang. On The Perfection of The Civil Service Incentive Mechanism [J]. Theory Report Era: The Academic Version, 2015, (4): 369-370.

[9] Wang Yan. The Innovation of Civil Service Incentive Mechanism [J]. Scientific and Technological Innovation and Application, 2015, 14 (14): 251-253.

[10] Chen Ling. Study on The Incentive Mechanism of Civil Servants: Model and Empirical [J]. Journal of Public Management, 2005, 2 (2): 87-91. 